\title{
The Study of Quality and Safety Traceability System of Vegetable Produce of Hebei Province
}

\author{
Fangzhou Wang ${ }^{1}$ and Wensheng Sun $^{2}$ \\ ${ }^{1}$ Business School, Agricultural University of Hebei \\ nuoyafangzhou0371@126.com \\ ${ }^{2}$ College of Economics and Trade, Agricultural University of Hebei \\ swen1001@yahoo.com
}

\begin{abstract}
To enhance the management of vegetable products quality and safety of Hebei Province, through practical research of vegetable enterprises, based on Web the authors design a quality and safety traceability system of vegetable products to enhance the monitoring of each participant in the production process. Combining the information and technology of the network and the reality of vegetable cultivation, applying the EAN $\bullet \mathrm{UCC}$ system, the authors draw up the traceability coding scheme of the vegetable products, design the quality traceability label of the vegetable products and achieve the traceability management of the vegetable products quality. The system can not only provide the detailed information inquiries of vegetable products for the consumers, but also provide a good operating platform for the production management and the monitoring quality and safety of vegetable products in the enterprises.
\end{abstract}

Keywords: Vegetable products, Quality and safety, Traceability system, EAN•UCC, Traceability label.

\section{Introduction}

Vegetables are the major source of vitamins, minerals and dietary fiber what the human body needs. With living standards improving, people become increasingly concerned about product quality and safety of vegetables. In recent years, our high pesticide residues in vegetables to make poisoning incidents occur from time to time. How to ensure the safety of vegetables, improve product quality and safety standards of the "food basket" and let urban and rural residents eat the safety in long, which is not only the focus of attention of ordinary people, but also an important condition for improving the competitiveness of vegetable industry.

\section{The Connotation of Quality and Safety of Vegetable Products}

Vegetables security is a relative concept, which has narrow and broad sense. Broad concept also includes the safety of quality, nutrition and genetically modified 
vegetables. Today the potential threats of genetically modified vegetables have not been well authenticated. Narrow concepts and standards include mainly four categories: (1) Pollution-free vegetables. These vegetables are that production environment, production process and product quality meet the related standards of pollution-free of the nation or agriculture, which are qualified and certified by the quality supervision and inspection institution, which have also the pollution-free food logo of the relevant department. (2) General products. It has not been particularly explained whether these vegetables are pollution-free food, green food and organic food or not, but today many countries have formulated the industry standard. (3) Green food. Following the principles of sustainable development, in accordance with the specific production methods, these vegetables can be permitted to use the green food mark which is identified by the specialized agencies. (4) Organic food. According to the international organic standards for agricultural production and corresponding processing requirements, these vegetables are the agricultural products that they are certified by the independent organic food certification agency.

Therefore, this article defined the vegetables safety in a narrow sense. As long as the toxic substances were in limited context, which include a pesticide residue, heavy metals, nitrates, harmful micro-organisms, parasite eggs, etc, they can be called safe vegetables.

\section{The Concept and Composition of Traceability System}

\subsection{The Concept of Traceability System}

According to the European Union definition of traceability system, it can be expressed as: "The continuity security system of information flow of food market in various stages". Popular that the system can track the interrelated information systems of the entire process from production, handling, processing, distribution and sale through each product bar codes and manage files to use modern management techniques.

\subsection{The Composition of Traceability System}

The application object of traceability system of vegetables product quality and safety is vegetable enterprises of production, supply and integration, which is made of the center management system, the subsystem of production base management, the subsystem of distribution center management, the public inquiries subsystems. The center management system as a server, the server has the subsystem of production base management and the subsystem of distribution center management [1]. If the public want to inquiry the subsystem, they need only to call the data of the center management system. The relationship structure of each subsystem can be seen from Figure 1. 


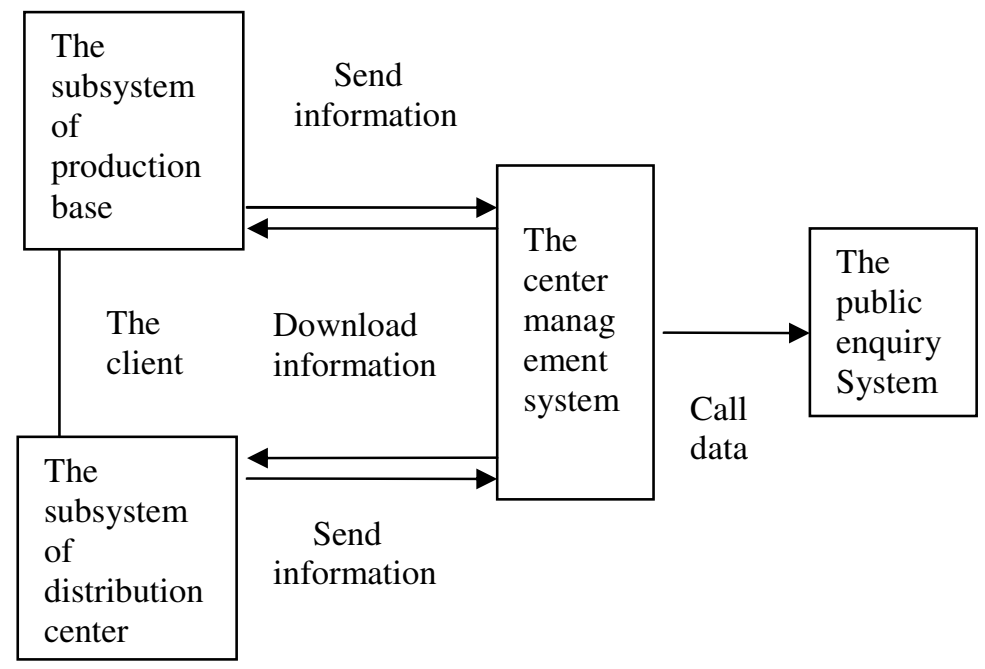

Fig. 1. The chart of Quality and Safety Traceability System of Vegetable Produce of Hebei Province

The center management system. The center management system is installed in the government administration, and the government is responsible for the management. The center management system is made of the corporate records, certification status, the base construction and the data center [2]. The center management system can finish the file management of enterprises operation and the production base, and it can also standardize and unify the production information, the information standards and the quality control information for vegetables.

The subsystem of production base management. The subsystem of production base management is installed in the vegetable production base, which includes the corporate records, the production management, the test management, the sales management and the data center. It can achieve the data management of production records management, product quality management, product sales management and production data base management. It also includes the distribution of agricultural land code and the seed, pesticide, fertilizer procurement, storage. At the same time, it can collect the quality information, automatically generate vegetable product trace label and print traceability code label.

The subsystem of distribution center management. The subsystem of distribution center management is installed in the vegetable distribution centers, which include business records, test management, sales management and data center. It mainly realizes the distribution and sales management of vegetable products in the vegetable production enterprises. It also realizes the delivery from the wholesale packaged product to the retail them and print retrospective code label.

The subsystem of public inquiries. The subsystem of public inquiries links to the Internet, which is a module subsystem of single function. It provides a platform of vegetable traceability code through the Internet. The public can check the enterprises of vegetables production, production base, harvest dates, as well as the information 


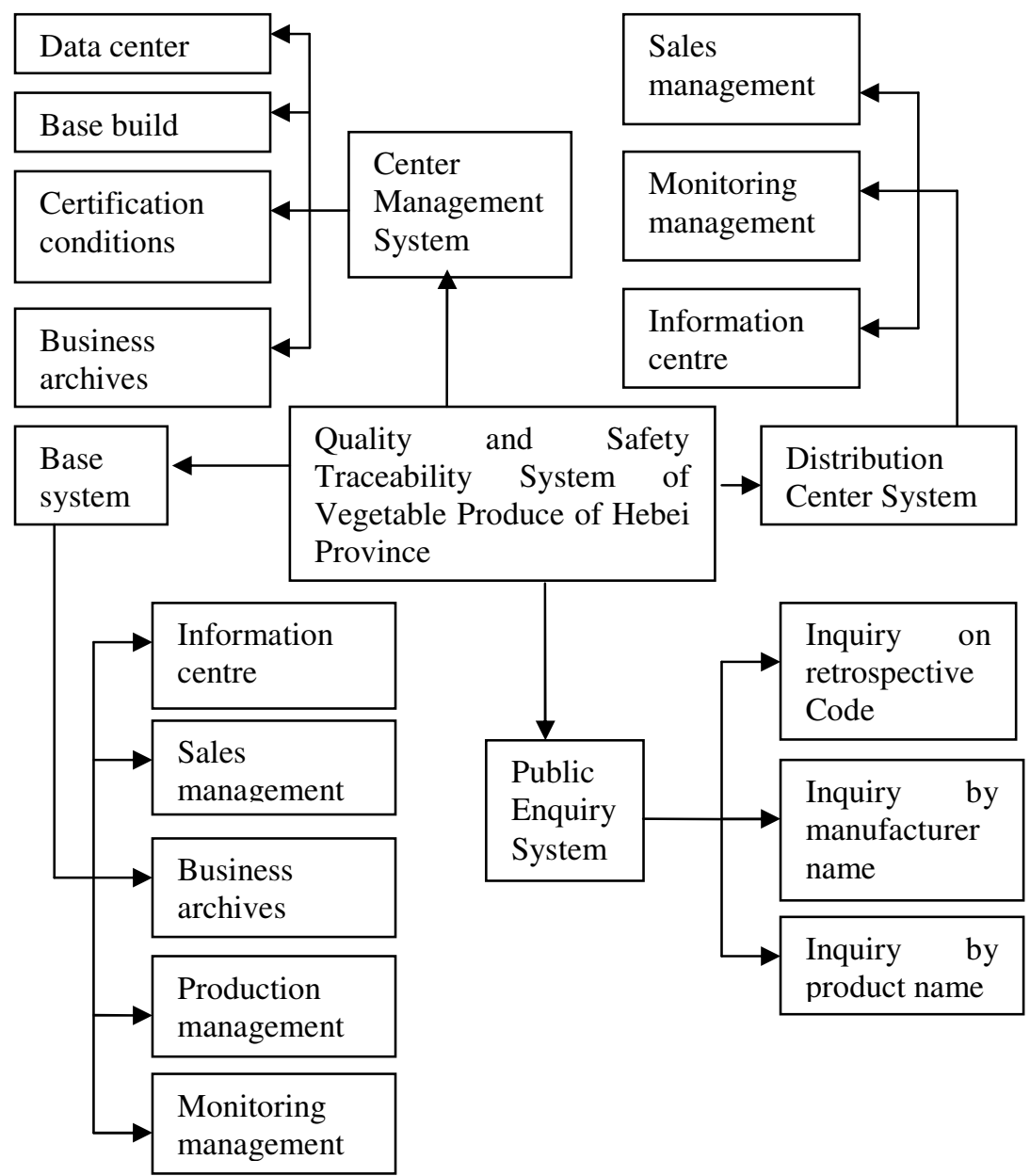

Fig. 2. The block diagram of quality and safety traceability system of vegetableproduce of Hebei Province

of the vegetable seed, fertilizer and pesticide. It can also search the vegetable information through the traceability code of vegetables names and enterprises names.

\section{The Traceability Code Design of Vegetable Produce Quality and Safety of Hebei Province}

According to the request of traceability code for the amount of information, drawing on existing experience, we choose EAN/UCC-128 bar code as the vegetable traceability code [3]. We also adopt GB/T16986-2003 " Application identifier of EAN•UCC system " standard to set the appropriate application identifier, the trade item identifier using AI (01) to identify the vegetable product identification code, the 
Table 1. The coding table of vegetable varieties in Hebei Province (part)

\begin{tabular}{ccc}
\hline $\begin{array}{l}\text { Vegetables } \\
\text { category }\end{array}$ & Vegetable varieties & Variety code \\
\hline \multirow{2}{*}{ Cabbage } & Chinese cabbage & 01010 \\
& Cabbage & 01040 \\
& Seaweed stalk & 01050 \\
Brassica & Stalk vegetables & 01060 \\
& Cabbage brassica & 02010 \\
& Cauliflower & 02020 \\
Melon & Cucumber & 05010 \\
& Melon & 05020 \\
& Loofah & 05030 \\
Eggplant & Bitter melon & 05040 \\
& Chili & 06010 \\
& Sweet pepper & 06020 \\
\hline
\end{tabular}

production date identifier using AI (11) to identify the production date, with the source entity reference code identifier AI (251) to identify the farmland code.

\subsection{The Identification Code of Vegetable Products}

The trade item identifier AI (01) indicates the meaning of the data segment is the global trade item codes (Global Trade Item Number, for short GTIN). We have chosen the EAN • UCC-13 code structure as an example.

\subsection{The Production Date Code}

The production date identifier AI (11) indicates the meaning of data segment is the production date of trade item. For vegetable products, the production date is the picking date, whose coding structure adopts YYYYMMDD format [4].

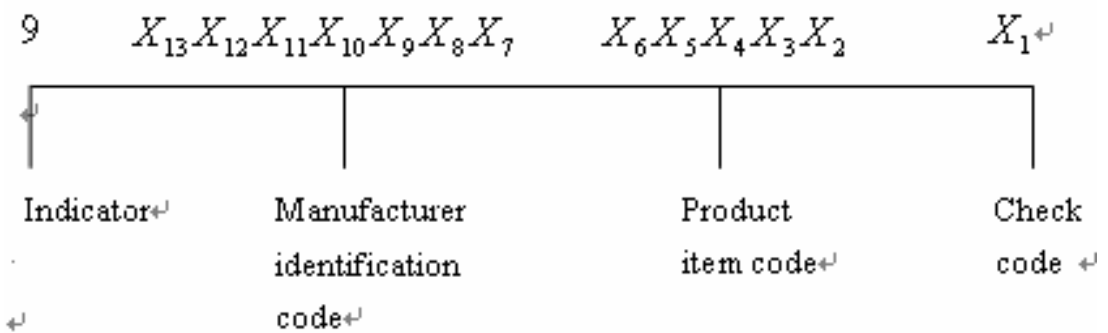

Fig. 3. The coding structure of EAN/UCC-13 


\subsection{The Field Code}

The data segment meaning of field identifier of source entity reference code AI (251) is the source entity reference code of trade item for tracking the original source of trade item. For vegetable products, the farmland number is the field code. The field codes are distributed by the manufacturer, but they should ensure every code is unique. The vegetable products that they are same field with the growing code are identical in the same period of the planting process. Six numbers, letters or numbers and letters mixed consists of the field code [5].

We use Cabbage code of a vegetables enterprise as an example.

(01) 96909999010403 (11) 20100415 (251) A1604

(01): Application indentifier; 9: Indicator; 6909999: Manufacturers identification code; 01040: Variety code; 3: Check code; (11): Production date application identification code; 20100415: Production date; (251): Field code application indentifier; A1604: Field number.

If a vegetable production enterprise code is "6909999", the product code of Chinese cabbage can be shown in Figure 4. It was picked in April 15, 2010, whose field code is A1604.

The traceability code is unique as the information carriers of vegetable products. While providing the product information, the origin and production date information, it meets the code standard of EAN • UCC.

\subsection{The Traceability Label Design of Vegetable Products Quality}

The vegetable product packaging is usually relatively simple, usually using plastic baskets, foam boxes, cartons, plastic bags or mesh bags as package after picking. The processing and distribution sectors use usually plastic bags, bandages as package, therefore, the label design should be short as much as possible, so that the bar code symbol distort little [6]. From the cost view, the label should be as small as possible,

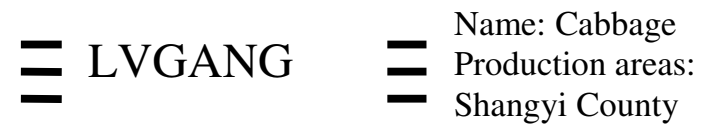

Shijiazhuang Dijie Ecological Agriculture

Development Co., Ltd

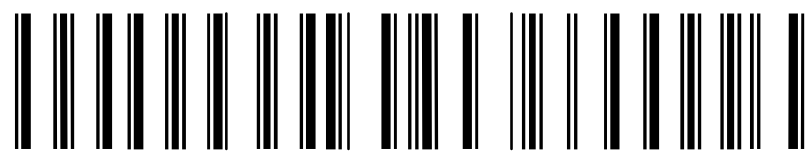

(01) 96909999010403 (11) 20100415 (251) A1604

Fig. 4. The traceability label of vegetable product quality of Hebei province 
but it should contain enough information. Giving adequate consideration to the circulation, the traceability label of vegetable product should also contain business name, origin and vegetable varieties. Based on enterprises, origin, date and vegetable varieties, the traceability code of vegetable product will automatically generate.

\section{The Operation of Traceability System}

The traceability system of quality and safety of vegetable products has been applied. The center management system has been installed in the quality inspection station of pollution-free agricultural products in Shijiazhuang. It can effectively monitor the vegetable production, circulation and quality information in the production base to establish the credit management files. Its main is the identity management, responsible management and credit management, while the function as the server can be successfully achieved for the security of management and organization, stability and orderly in the entire system and database. The management subsystem of production base is installed in the vegetable product base of the Shijiazhuang Dijie Ecological Agriculture Co., Ltd. It can make the traceability label automatically generate, and it can also make the print functions smoothly realize. The distribution centre management subsystem has been installed in the distribution centre of the Shijiazhuang Dijie Ecological Agriculture Co., Ltd. It can make the whereabouts information collection and delivery of vegetable sales reliable. The subsystem of public inquiry links to the Internet of quality and safety of vegetable product in Shijiazhuang. The consumers can quickly and easily inquire the information of quality and safety on vegetable product through the Internet.

\section{Discuss}

The traceability system should be established on the basis of production processes, but the mechanization level of production process is not high in the most enterprises of Hebei Province, which are mainly manual production. Therefore, when the traceability system protects the quality and safety of vegetable products, it needs more the control steps and the various factors of affecting the quality and safety of vegetable products. Based on production process to establish the traceability system, we want to learn fully each process and monitor and record the information to complete the traceability chain. The traceability system of complete supply chain should also involve the wholesalers, retailers and ultimately consumers. Today the scope of traceability system becomes larger and larger. The docking and coordination the individual information of different levels will increase the more difficulty for traceability system. Our project is developing the connectivity of the distribution, supply chain etc to form a more perfect traceability system of vegetable products.

The future development direction is digital management adopting the information technology for the vegetable production circulation, but now general agricultural and high-quality, safe agricultural products are coexist to increase the vegetable products costs. If we fully promote this system, beyond the capacity of the market, it will affect the effectiveness of the system's application to make the further application of the 
system become difficult. Government departments should support and guide actively, regulate the market and vigorous propaganda from point to area to push gradually the implementation of quality and safety of the traceability system.

\section{References}

1. Davis, J.R., Dikeman, M.E.: Practical aspects of beef carass traceability non-commercial beef processing plant using an electronic identification system. J. Journal Animal Science (supplement), 47-48 (2002)

2. Petersen, B., Deszczka, K., Schmidte, P.: Computerised food safety monitoring in animal production. J. Live stock Production Science 76, 207-213 (2002)

3. Stanford, K., Stitt, J., Kellar, J.A.: Traceability in cattle and small ruminants in Canada. J. Scientific and Technical Review 20(2), 510-522 (2001)

4. Xinting, Y., Chuanheng, S., Jianping, Q.: The design and application of the quality traceability label in the food safety control. J. Chinese Agricultural Science Bulletin 22(5), 98-101 (2006)

5. Xiao, F.: The traceability system of vegetable quality and safety-Based on Web. J. Computer Engineering and Design 1, 23-24 (2009)

6. Shan, W.: The process quality control of vegetable production from plough to table. J. Agricultural Sciences of Jiangsu 6, 18-19 (2009) 